\title{
ASO Visual Abstract: Multidisciplinary Intervention in Radiation-Associated Angiosarcoma of the Breast: Patterns of Recurrence and Response to Treatment
}

\author{
Sheena Guram, MBBS, MSc', Andrea M. Covelli, MD, PhD ${ }^{1}$, Anne C. O'Neill, MBBCh, PhD' ${ }^{2}$, \\ David B. Shultz, MD, $\mathrm{PhD}^{3}$, Elizabeth G. Demicco, MD, $\mathrm{PhD}^{4}$, Abha A. Gupta MD, $\mathrm{MSc}^{5}$, and \\ Rebecca A. Gladdy, MD, PhD ${ }^{1}$
}

${ }^{1}$ Division of Surgical Oncology, Department of Surgery, Mount Sinai Hospital and Princess Margaret Cancer Centre, University of Toronto, Toronto, ON, Canada; ${ }^{2}$ Division of Plastic and Reconstructive Surgery, Department of Surgery, Mount Sinai Hospital and University Health Network, University of Toronto, Toronto, Canada; ${ }^{3}$ Department of Radiation Oncology, Princess Margaret Cancer Centre, University of Toronto, Toronto, Canada; ${ }^{4}$ Department of Pathology and Laboratory Medicine, Department of Pathobiology and Laboratory Medicine, Mount Sinai Hospital, University of Toronto, Toronto, Canada; ${ }^{5}$ Division of Hematology/Oncology, The Hospital for Sick Children and Princess Margaret Cancer Centre, Toronto, Canada

As reported in our article (https://doi.org/10.1245/s104 34-021-10477-1), radiation-associated angiosarcoma treatment at a sarcoma center was associated with more extensive surgery, multimodal treatments, and higher
3 -year recurrence-free survival. Salvage after recurrence is possible, as $1 / 4$ of patients were alive without disease after treatment for recurrence.

\section{Multidisciplinary Intervention in Radiation-Associated Angiosarcoma} of the Breast: Patterns of Recurrence and Response to Treatment

Patients Undergoing Resection for Radiation Associated Angiosarcoma (RAAS) (N=49)

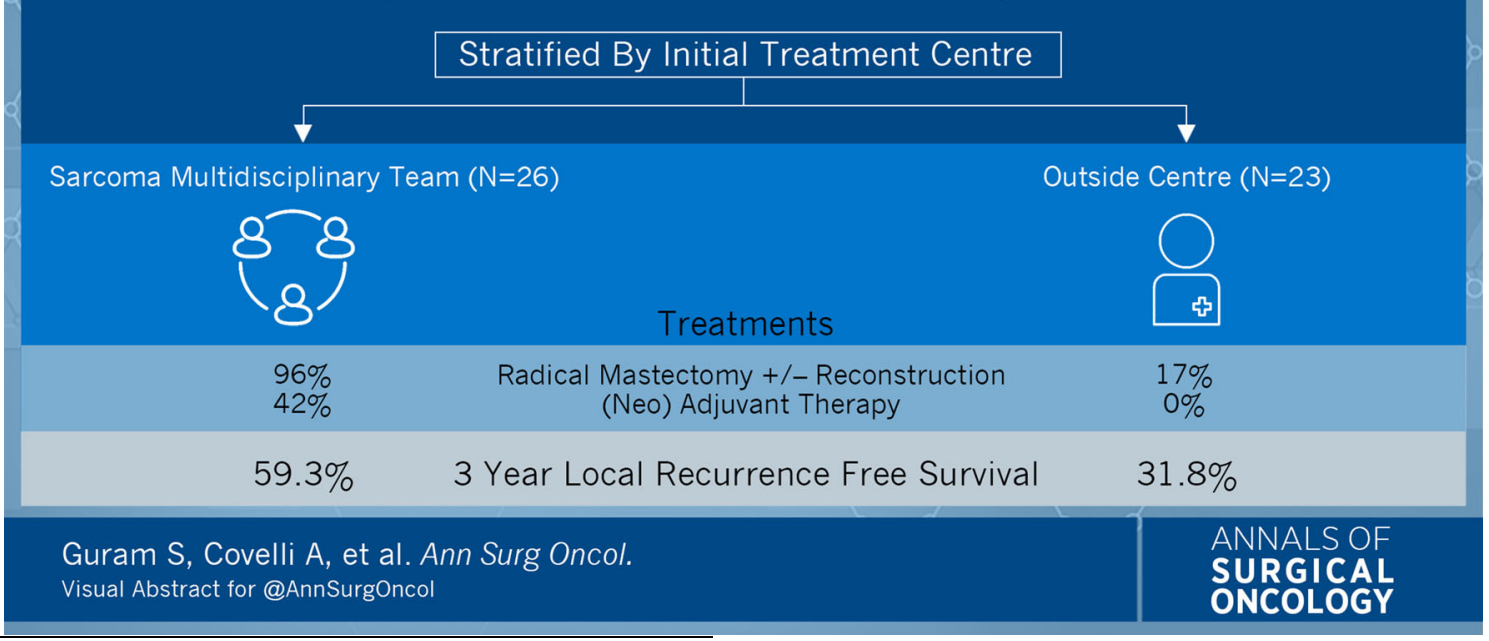

Sheena Guram and Andrea M. Covelli: Shared primary first authors.

DISCLOSURES None.

(C) Society of Surgical Oncology 2021

Published Online: 17 August 2021

R. A. Gladdy, MD, PhD

e-mail: rebecca.gladdy@sinaihealth.ca
Publisher's Note Springer Nature remains neutral with regard to jurisdictional claims in published maps and institutional affiliations. 